\title{
The Game Analysis of Manufacturers' Political Connections on Product Safety in Supply Chain: Evidence from China
}

\author{
Zhao Na and Wang Fusheng \\ School of Management, Harbin Institute of Technology, Harbin 150001, China \\ Correspondence should be addressed to Wang Fusheng; wangfushenghit@sohu.com
}

Received 18 June 2013; Revised 20 September 2013; Accepted 29 October 2013

Academic Editor: Tinggui Chen

Copyright ( 2013 Z. Na and W. Fusheng. This is an open access article distributed under the Creative Commons Attribution License, which permits unrestricted use, distribution, and reproduction in any medium, provided the original work is properly cited.

\begin{abstract}
This paper studied the political connections on product safety in supply chain. In market economy, information asymmetry exists throughout the entirety of supply chains that ought to ensure product safety. Due to the existence of game relations between the government and manufacturers in the aspects of product safety and regulation, the formation of market equilibrium depends on political connections between the government and manufacturers. Based on study and analyses of a static game model and a dynamic game model, this paper reveals that governments and manufacturers must use positive political connections to achieve product protection and supervision of safety throughout the supply chain. On the other hand, negative political connections lead to losses of both governmental credibility and social profits. This study indicates that inherent mechanism of political connections exists in the supply chain; it will help to enrich the theory of supply chain.
\end{abstract}

\section{Introduction}

Product safety is an issue of utmost importance all around the world and it is related to the supply chain in its entirety. The situation brings some new problems to traditional supply chain [1]. As the world's second largest economy, with frequent international business and a large population, China considers product safety a top priority. Product safety affects not only national credibility and the credibility of companies but also the important basic commitments of a nation and its enterprises for users. However, because of information asymmetry, product users require product manufacturers to be highly disciplined and require strict supervision and management of government departments. "Product" refers to everything available in the market that can meet the specific needs of people, including in-kind, service assurance, ideas, and other forms. "Security" refers to the conditions that prevent death, injury, occupational diseases, equipment damage, property damage, and environmental damage.

Ensuring the safety of products first depends on sound laws and regulations. In addition, government departments must work with the law, enforce the law, properly regulate rules, and abandon favoritism or irregularities. Second, the manufacturers should develop and enforce their own techniques for ensuring production quality, sustaining the self-regulation of the industry, and maintaining the professional ethics of the employed. In order to strengthen the safety supervision of special equipment, prevent accidents, ensure the safety of people's lives and property, and promote economic development, China has made related laws to constrain product safety issues, such as Article 5 in the Constitution of the People's Republic of China, Article 146 in the PRC Criminal Law, and Article 14, Article 15, Article 49, and Article 50 in the PRC Product Quality Law. However, laws and regulations are a double-edged sword. When they are supposed to serve a function in binding constraints to protect the majority of people, the government appears to use administrative powers to participate in certain economic activity concerning political connections with enterprises, thus creating opportunities for a few privileged persons to achieve excess revenue. According to the statement of two economists, Buchanan and Krueger, this excess revenue is called "rent". The activities of seeking authority to obtain rent are called "rent-seeking activities" $[2,3]$.

Therefore, to pursue increased benefits, manufacturers circumvent or address legal and regulatory risks so that 
certain people obtain privileges and excess revenue via rentseeking activities that establish political connections with the government. Political connection is different from the government intervention. It is a dynamic interaction of the relationship between government and enterprises. Generalized political connections: it is described in order to achieve the enterprise or individual interests, and the government directly or indirectly is related to the collective or individual behavior. Narrow political connections: it refers to the existence of a political background of personnel in the enterprise shareholders, board of directors, and management. These political connections link the interests of enterprise, government, and individual. The definition of political connections in this paper takes into account the standard definitions used in the literature. Agrawal and Knoeber show that politically experienced directors might affect their performance in U.S. manufacturing firms [4]. Khwaja and Mian bring to light the role of ex-politicians in providing government bank loans to politically connected firms [5]. Fan et al. define a Chinese firm as being politically connected if the CEO is a current or former officer of the central government, local government, or the military [6]. Ferguson and Voth consider firms to be political connections if the executives and supervisory board members were close to the ruling party [7]. Our definition of political connections uses the special political connections; it covers current and former political connections research. The root of rent originates from the formation of price differences because demand increases for this kind of production factor, whereas supply cannot increase due to various other factors. However, Kruger believes that rent seeking is a dredging activity conducted to obtain licenses and quotas to gain additional revenue. Therefore, political connections will have a positive effect on firm value as a rent-seeking behavior of enterprise [8], it will help enterprises on product safety in supply Chain process.

From the perspective of game theory [9], by building static and dynamic game models, this paper analyzes the game relationship of how political connections between government and manufacturers mutually restrain and make contact with each other on product safety in supply chains. It also reveals that political connections between the government and manufacturers are crucial in product safety in the product supply chain, and both sides need to collaborate with each other and fulfill their duties to better ensure product safety throughout the entire supply chain [10]. This paper for the first time mentions political connections in supply chain and introduced the theory of political connections into supply chain theory. It will not only enrich the research of supply chain and political connections, but also will reveal the internal mechanism about political connections on safety production in supply chain system.

\section{Static Game between the Government and Manufacturers}

2.1. Establishment of the Static Model. Consider the behavior of political connections on safety production in supply chain. We need to clear the behavior of the participants, namely,
TABLE 1: Game matrix of the government and manufacturers.

\begin{tabular}{lcc}
\hline Manufacturers & \multicolumn{2}{c}{ Government } \\
& Supervision $p_{1}$ & $\begin{array}{c}\text { Nonsupervision } \\
1-p_{1}\end{array}$ \\
\hline Value product safety $p_{2}$ & $M-C_{2},-C_{1}$ & $M-C_{2}, 0$ \\
Neglect product safety $1-p_{2}$ & $-C_{3}, C_{3}-C_{1}$ & $0,-C_{5}$ \\
\hline
\end{tabular}

TABLE 2: Game matrix of the government and manufacturers.

\begin{tabular}{lcc}
\hline Manufacturers & \multicolumn{2}{c}{ Government } \\
& Supervision $p_{1}$ & $\begin{array}{c}\text { Nonsupervision } \\
1-p_{1}\end{array}$ \\
\hline Value product safety $p_{2}$ & $M-C_{2},-C_{1}$ & $-C_{3}, C_{3}-C_{1}$ \\
Neglect product safety $1-p_{2}$ & $M-C_{2}, 0$ & $0,-C_{4}-C_{5}$ \\
\hline
\end{tabular}

the government and manufacturers as well as their behavior in the supply chain production. Static game is the principle that actors either participate in the selection simultaneously or, if they are not in the same selection, the latter actor does not know the specific action that had been taken earlier in the game. The game between the government and manufacturers constitutes a static game with complete information [11].

Assumptions: (a) the cost used by the government to monitor the safe behavior of manufacturers by administrative, economic, legal, and other means is $C_{1}$, and its probability is $p_{1}$; (b) if manufacturers can recognize the importance of product safety, fulfill quality commitment, and actively cooperate with government regulations, the cost paid should be $C_{2}$, and the intangible benefit brought by credibility is $M$, which has a probability of $p_{2}$; (c) if manufacturers focus only on short-term interests and behave contrarily to industry ethics, the cost of compulsory fines, legal responsibilities, and the damage of social image resulting from product safety issues is $C_{3}$; (d) the lost social cost when negative political connections are established between the government and manufacturers, which means that governmental officials profit by ignoring product safety issues as companies label substandard products as fine products under the security umbrella of government to obtain excess revenue, should be $\mathrm{C}_{4}$; the cost of losing the governmental credibility is $C_{5}$.

The political game matrix between manufacturers and government is shown in Table 1.

Under the assumption that worldwide concerns on product safety continue to increase, if the government does not handle the product safety issues of manufacturers properly, the government's image will incur damage. When $C_{5}$ is smaller than $C_{1}-C_{3}$, Nash equilibrium occurs (ignoring product safety and supervision). The lost social cost $C_{4}$ caused by negative political connections should be attributed to the government because the loss of social cost is much greater than the cost when the government fulfills regulatory responsibilities, which is $C_{1}-C_{3}<C_{1}<C_{4}$. Therefore, social pressure prompts the government to use various means to regulate and constrain product safety issues. The game matrix of the political connections between the government and manufacturers is shown in Table 2. 
2.2. Solving the Game Model. The expected revenue function of political connections between manufacturers and the government is shown by the following:

$$
\begin{aligned}
E_{G}= & p_{1}\left[-p_{2} C_{1}+\left(1-p_{2}\right)\left(C_{3}-C_{1}\right)\right] \\
& +\left(1-p_{1}\right)\left(1-p_{2}\right)\left(-C_{4}-C_{5}\right), \\
E_{G}= & p_{2}\left[p_{1}\left(M-C_{2}\right)+\left(1-p_{1}\right)\left(M-C_{2}\right)\right] \\
& -\left(1-p_{2}\right) p_{1} C_{3} .
\end{aligned}
$$

The solved mixed strategy Nash equilibrium [12] is

$$
\left(p_{1}^{*}=\frac{C_{2}-M}{C_{2}}, p_{2}^{*}=1-\frac{C_{1}}{C_{3}+C_{4}+C_{5}}\right) \text {. }
$$

The relation between $p_{1}^{*}$ and $p_{2}^{*}$ is

$$
p_{2}^{*}=1-\frac{p_{1}^{*} C_{1}}{C_{2}-M+C_{4} p_{1}^{*}+C_{5} p_{1}^{*}} .
$$

The first derivative of $p_{1}^{*}$ is

$$
p_{2}^{* \prime}=\frac{C_{1}\left(M-C_{2}\right)}{\left(C_{2}-M+C_{4} p_{1}^{*}+C_{5} p_{1}^{*}\right)^{2}}
$$

When $M-C_{2}>0, M>C_{2}, p_{2}^{*^{\prime}}>0$, and $p_{2}^{*}$ is an increasing function.

2.3. Results Analysis. Equation (3) shows that the smaller the governmental regulatory cost $C_{1}$, the greater the social cost $C_{4}$ and the lost credibility $C_{5}$ caused by the government defaulting and the greater the $p_{2}$ probability of manufacturers valuing product safety.

Equation (4) shows that when the profits a company gains due to probability are greater than its cost of protection, the probability $p_{2}$ of valuing the product increases along with the rising of probability $p_{1}$ of the supervision of the government.

\section{Dynamic Game between the Government and Manufacturers}

Dynamic game means that the actions of persons involved follow an order and that the action of the former person can be observed by the latter. Based on the inaccuracy of the information, such as the characteristics of other participants, the strategy space, and payoff function and the principle of order and repeating a game includes, the game between the government and manufacturers constitutes a dynamic game of incomplete information.

3.1. Establishment of the Dynamic Game Model. Assumptions: (a) the cost used by the government to monitor the safe behavior of manufacturers by administrative, economic, legal, regulatory, and other means is $C_{1}$, and its probability is $p_{1}$; (b) if the manufacturers can recognize the importance of product safety and actively cooperate with government regulations, the cost paid should be $C_{2}$, and the intangible

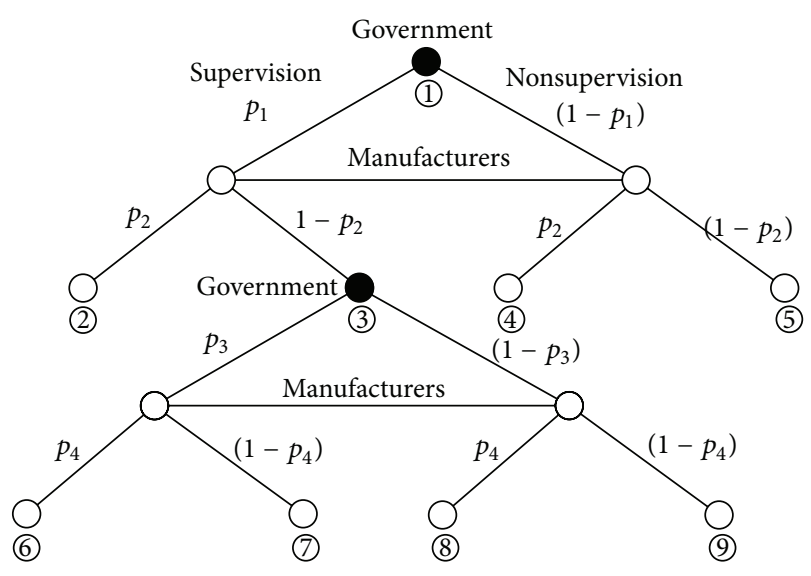

FIGURE 1: Game tree of government and the manufacturers.

benefit brought by credibility is $M_{1}$, which has a probability of $p_{2}$; if manufacturers focus only on short-term interests and behave contrarily to industry ethics, the cost of compulsory fines and legal responsibilities resulting from product safety issues is $C_{3}$, and the cost of the credibility is $C_{4}$; (c) in the case that the government abuses authority (with a probability $p_{3}$ ), if the manufacturers do not attach importance to product safety and bribe. $\varphi C_{2}(0<\varphi<1)$ the relevant government officials in order to avoid punishment, the probability of bribery is $p_{4}$. If the relevant government officials take the bribes $\varphi C_{2}$ of manufacturers as their own revenue, the loss of credibility is $C_{5}$; under the condition that manufacturers neither attach importance to product safety nor to bribing the government, the fine charged from manufacturers by the relevant government officials because of abuse of authority should be $\gamma C_{3}, \gamma>1$; (d) if the relevant government officials do not abuse their authority, instead they will submit the bribe $\varphi C_{2}$ and the fine $C_{3}$ to the treasury on their own initiative, and the government will give proper incentives $\gamma\left(\varphi C_{2}+\right.$ $C_{3}$ ) $0<\gamma<1$ for them; (e) relevant government officials do not supervise and manufacturers do not attach importance to product safety, causing serious impact on society. Losses caused by the defaulting of relevant government officials are $C_{6}$ (including loss of credibility and the resulting loss of social costs). The game tree of the government and the manufacturers is shown in Figure 1.

Revenue of each node in the game tree:

$$
\begin{aligned}
& \text { (1) }\left(E_{21}, E_{22}\right) \\
& \text { (2) }\left(-C_{1}, M_{1}-C_{2}\right) \\
& \text { (3) }\left(E_{11}, E_{12}\right) \\
& \text { (4) }\left(0,-C_{2}\right) \\
& \text { (5) }\left(-C_{6}, 0\right) \\
& \text { (6) }\left(-C_{1}+\varphi C_{2}-C_{5},-\varphi C_{2}-C_{4}\right) \\
& \text { (7) }\left(-C_{1}+\omega C_{3}-C_{5},-\omega C_{3}-C_{4}\right) \\
& \text { (8) }\left(-C_{1}+\gamma\left(\varphi C_{2}+C_{3}\right),-\varphi C_{2}-C_{3}-C_{4}\right) \\
& \text { (9) }\left(-C_{1}+\gamma C_{3},-C_{3}-C_{4}\right) .
\end{aligned}
$$


3.2. Seeking Nash Equilibrium in Dynamic Game Problem. This backward induction method is for this dynamic game problem to seek the equilibrium value. Firstly, expectation of node (3) is computed. Consider

$$
\begin{aligned}
E_{11}= & p_{3} p_{4}\left(-C_{1}+\varphi C_{2}-C_{5}\right) \\
& +p_{3}\left(1-p_{4}\right)\left(-C_{1}+\omega C_{3}-C_{5}\right) \\
& +\left(1-p_{3}\right) p_{4}\left[-C_{1}+\gamma\left(\varphi C_{2}+C_{3}\right)\right] \\
& +\left(1-p_{3}\right)\left(1-p_{4}\right)\left(-C_{1}+\gamma C_{3}\right), \\
E_{12}= & p_{3} p_{4}\left(-\varphi C_{2}-C_{4}\right) \\
& +p_{3}\left(1-p_{4}\right)\left(-\omega C_{3}-C_{4}\right) \\
& +\left(1-p_{3}\right) p_{4}\left(-\varphi C_{2}-C_{3}-C_{4}\right) \\
& +\left(1-p_{3}\right)\left(1-p_{4}\right)\left(-C_{3}-C_{4}\right) .
\end{aligned}
$$

The Nash equilibrium of formula (5) and formula (6) is sought as follow:

$$
\begin{aligned}
\frac{\partial E_{11}}{\partial p_{3}}= & p_{4}\left(-C_{1}+\varphi C_{2}-C_{5}\right)+\left(1-p_{4}\right) \\
& \times\left(-C_{1}+\omega C_{3}-C_{5}\right) \\
& -p_{4}\left[-C_{1}+\gamma\left(\varphi C_{2}+C_{3}\right)\right] \\
& -\left(1-p_{4}\right)\left(-C_{1}+\gamma C_{3}\right)=0, \\
\frac{\partial E_{12}}{\partial p_{4}}= & p_{3}\left(-\varphi C_{2}-C_{4}\right)-p_{3}\left(-\omega C_{3}-C_{4}\right) \\
& +\left(1-p_{3}\right)\left(-\varphi C_{2}-C_{3}-C_{4}\right) \\
& -\left(1-p_{3}\right)\left(-C_{3}-C_{4}\right)=0, \\
\left(p_{3}^{*}=\right. & \left.\frac{\varphi C_{2}}{\omega C_{3}}, p_{4}^{*}=\frac{(\gamma-\omega) C_{3}+C_{5}}{\varphi(1-\gamma) C_{2}-\omega C_{3}}\right) .
\end{aligned}
$$

Substituting $\left(p_{3}^{*}, p_{4}^{*}\right)$ into formula (5) and formula (6), we can obtain

$$
\begin{gathered}
E_{11}^{*}=-C_{1}+\alpha \gamma p_{4}^{*} C_{2}+\gamma C_{3}, \\
E_{12}^{*}=\frac{\varphi(1-\omega)}{\omega} C_{2}-C_{3}-C_{4} .
\end{gathered}
$$

Second, the expected value of node (1) is calculated as follow:

$$
\begin{gathered}
E_{21}=-p_{1} p_{2} C_{1}-\left(1-p_{1}\right)\left(1-p_{2}\right) C_{6}+p_{1}\left(1-p_{2}\right) E_{11}^{*}, \\
E_{22}=-\left(1-p_{1}\right) p_{2} C_{2}+p_{1} p_{2}\left(M_{1}-C_{2}\right)+p_{1}\left(1-p_{2}\right) E_{12}^{*} .
\end{gathered}
$$

We can seek the Nash equilibrium of the game problem as follow:

$$
\begin{gathered}
\frac{\partial E_{21}}{\partial p_{1}}=-p_{2} C_{1}+\left(1-p_{2}\right) C_{6}+\left(1-p_{2}\right) E_{11}^{*}=0 \\
\frac{\partial E_{22}}{\partial p_{2}}=-\left(1-p_{1}\right) C_{2}+p_{1}\left(M_{1}-C_{2}\right)-p_{1} E_{12}^{*}=0 .
\end{gathered}
$$

Nash equilibrium obtained is

$$
\left(p_{1}^{*}=\frac{C_{2}}{M_{1}-E_{12}^{*}}, p_{2}^{*}=\frac{C_{6}+E_{11}^{*}}{C_{1}+C_{6}+E_{11}^{*}}\right) \text {. }
$$

3.3. Results Analysis. (a) The probability of government regulation is related to the costs of valuing the product safety of manufacturers, the profits protecting the credibility, and their expectations. The more the manufacturers value the product safety cost $C_{2}$, the greater the probability of government regulation $p_{1}^{*}$. The greater the profit $M_{1}$ by protecting the credibility, the smaller the probability of government regulation $p_{1}^{*}$. The larger $E_{12}^{*}$ is, the greater the positivity of manufacturers' emphasis on product safety and the smaller the probability of government regulation $p_{1}^{*}$ will be.

(b) The probability of manufacturers' emphasizing product safety is related to the supervision costs, expected revenue, and credibility losses of the relevant government officials. The higher the government regulatory cost $C_{1}$ is, the smaller the $p_{2}^{*}$ is. The higher the expected revenue of relevant government officials in the first stage $E_{11}^{*}$, the bigger the $p_{2}^{*}$. The higher the loss of government credibility $C_{6}$, the bigger the $p_{2}^{*}$.

(c) The probability of relevant government officials abusing power is associated with the following factors: the bigger $\varphi$ the higher the bribe $\varphi C_{2}$ and the greater the temptation of relevant government officials. Thus, $p_{3}^{*}$ will be bigger. The greater the fines charged by the abusive government, the smaller the probability $p_{3}^{*}$ of abusing power of relevant government officials because the enterprises will begin to attach importance to product safety in order to avoid penalties.

(d) The probability $p_{4}^{*}$ of the bribery of manufacturers is connected with the following factors: when the incentive payments given to relevant government departments are disproportionate with the amount they turn into the state treasury, the relevant government officials will have greater tendencies to expend funds. Thus, the formation of rentseeking behavior between the government and manufacturers will be stimulated. The greater the probability $p_{4}^{*}$ of the bribery of manufacturers, the greater the loss $C_{5}$ of government credibility resulting from the abuse of power and the smaller the probability of bribery of manufacturers.

\section{Conclusion}

This paper for the first time mentions political connections in supply chain and introduces the theory of political connections into supply chain theory. It studied political connections of product safety in supply chain. Based on study and theoretical analyses of a static game model and a dynamic game model, first of all, this paper reveals the relationship between the degree of manufacturers who pay attention to product safety and government supervision of product safety cost, expected return, and credit loss size. Namely, both sides need to establish the positive political connection to maintain the credibility and promote the virtuous cycle of the production supply chain. On the other 
hand, the paper indicated the probability of a political contact person who breach of privilege depends on the bribes and the fine proportion. However, the probability of a production manufacturer who have offered bribes depends on the ratio of political contacts official income and grey income. Namely, both sides established the negative political ties. Although negative political connections are conducive to short-term interests on the surface, they are not conducive to the longterm development of enterprises and harmed governmental credibility and the social public interest.

This research will not only enrich the research of supply chain and political connections but also will reveal the internal mechanism about political connections on safety production in the research of supply chain system. In this paper, some problems need to be further studied. For example the model parameters need to be confirmed by real statistics data and a part of conditions of model was built on the basis of some rational hypothesis.

\section{References}

[1] Y. Luo, Y. Lou, and S. Wang, "Stackelberg game for product renewal in supply chain," Discrete Dynamics in Nature and Society, vol. 2013, Article ID 726536, 10 pages, 2013.

[2] J. M. Buchanan, The Demand and Supply of Public Goods, Rand McNally, 1968.

[3] A. O. Krueger, Political Economy of Policy Reform in Developing Countries, MIT Press, 1993.

[4] A. Agrawal and C. R. Knoeber, "Do some outside directors play a political role?" Journal of Law and Economics, vol. 44, no. 1, pp. 179-198, 2001.

[5] A. I. Khwaja and A. Mian, "Do lenders favor politically connected firms? Rent provision in an emerging financial market," Quarterly Journal of Economics, vol. 120, no. 4, pp. 1371-1411, 2005.

[6] J. P. H. Fan, T. J. Wong, and T. Zhang, "Politically connected CEOs, corporate governance, and Post-IPO performance of China's newly partially privatized firms," Journal of Financial Economics, vol. 84, no. 2, pp. 330-357, 2007.

[7] T. Ferguson and H.-J. Voth, "Betting on Hitler-the value of political connections in Nazi Germany," Quarterly Journal of Economics, vol. 123, no. 1, pp. 101-137, 2008.

[8] N. Zhao, F. Wang, and Q. Tang, "Game analysis on the motivations for political connections in China's listed companies based on a principal-agent model," Journal of Computational Information Systems, vol. 9-10, pp. 4155-4162, 2013.

[9] M. Rabin, "Incorporating fairness into game-theory and economics," American Economic Review, vol. 83, no. 5, pp. 12811302, 1993.

[10] G. P. Cachon and M. A. Lariviere, "Supply chain coordination with revenue-sharing contracts: strengths and limitations," Management Science, vol. 51, no. 1, pp. 30-44, 2005.

[11] N. Bakshi and N. Gans, "Securing the containerized supply chain: analysis of government incentives for private investment," Management Science, vol. 56, no. 2, pp. 219-233, 2010.

[12] J. F. Nash, "Equilibrium points in N-person games," Proceedings of the National Academy of Sciences of the United States of America, vol. 36, no. 1, pp. 48-49, 1950. 


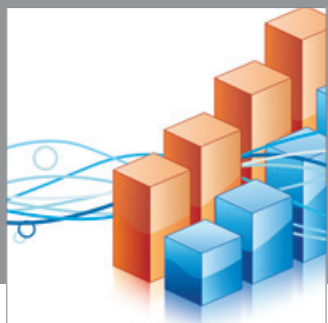

Advances in

Operations Research

mansans

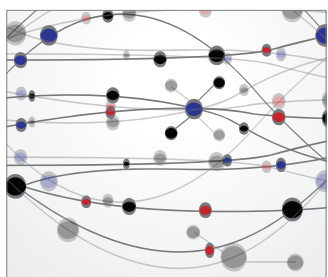

The Scientific World Journal
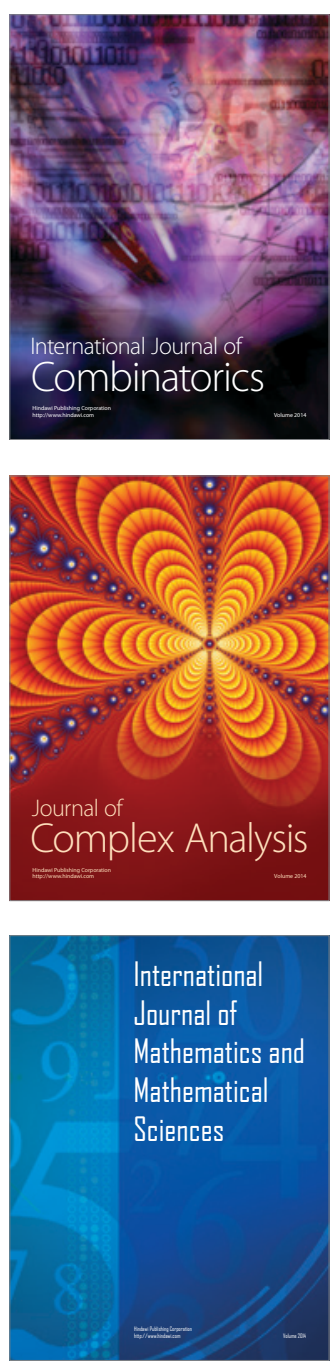
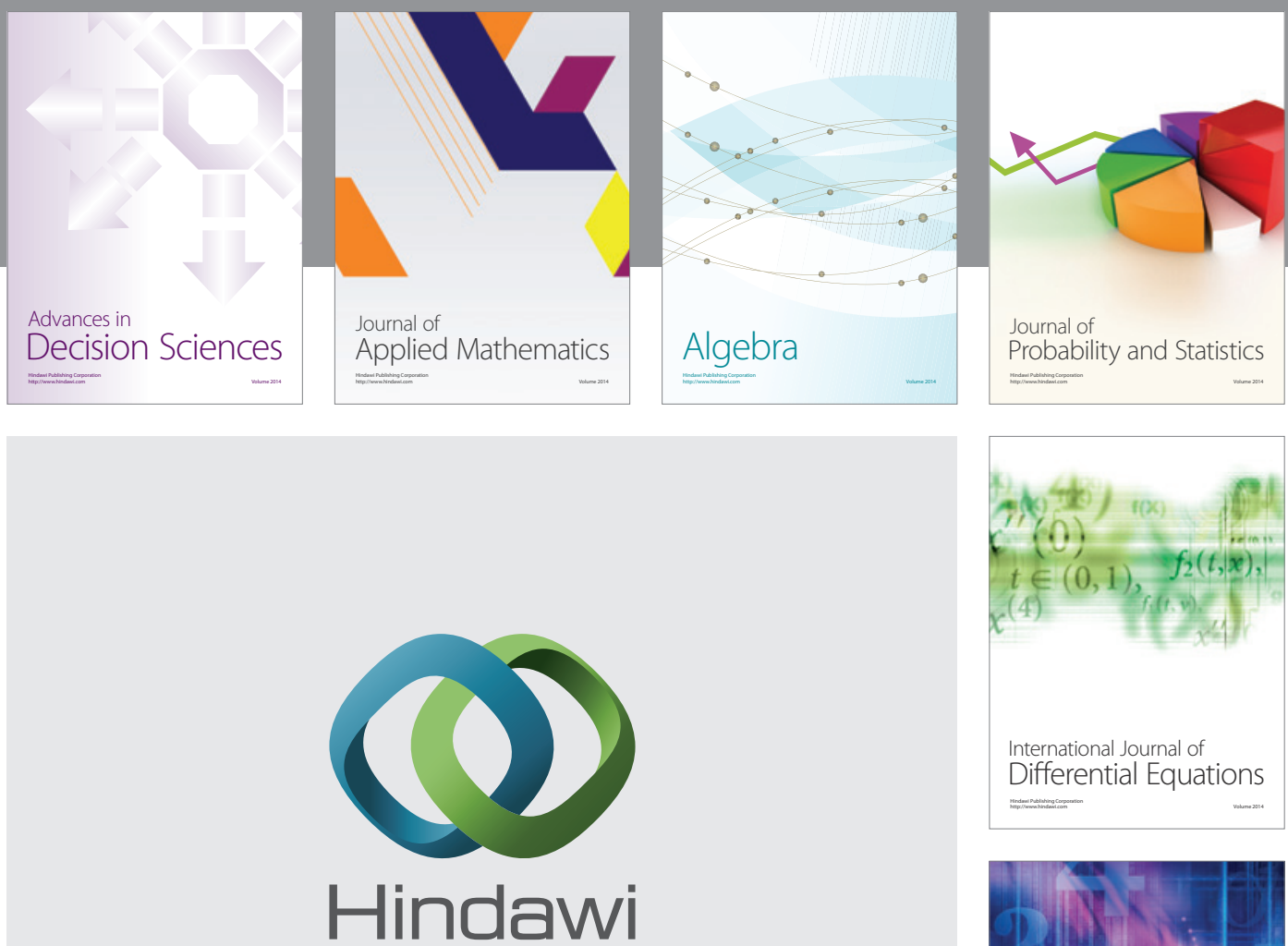

Submit your manuscripts at http://www.hindawi.com
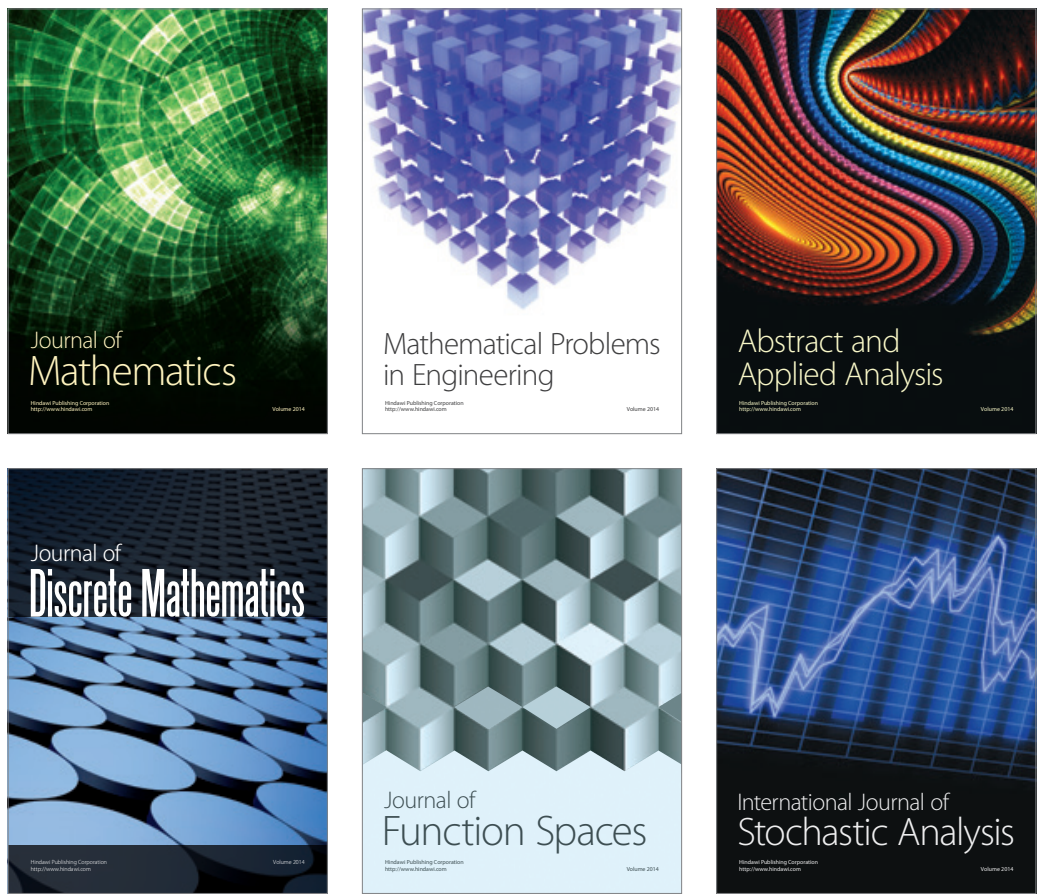

Journal of

Function Spaces

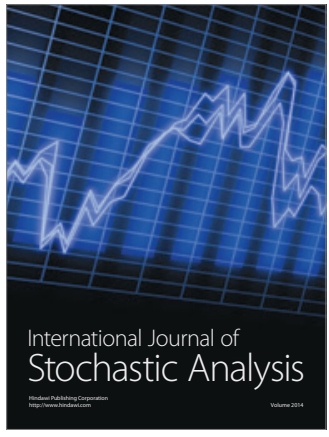

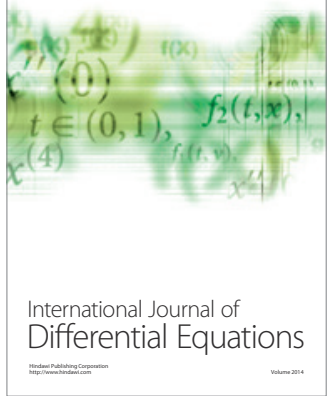
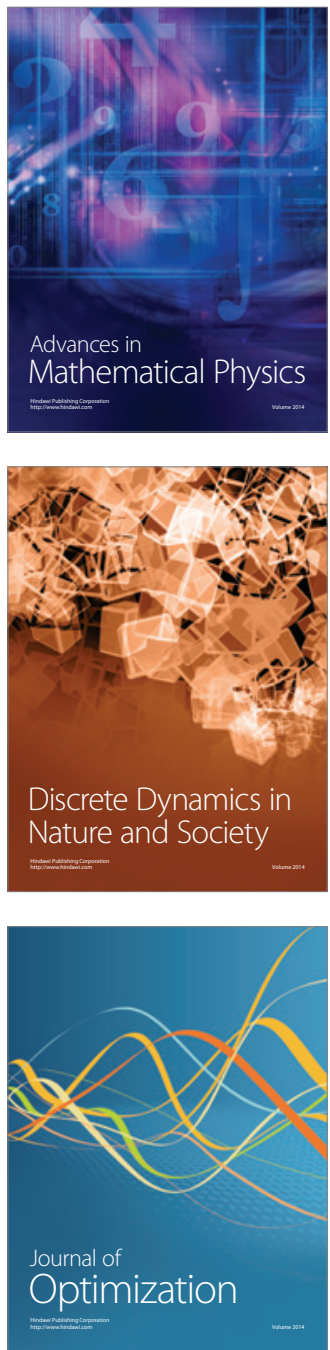